program, Infectious Disease Division and related services are fully integrated with those of MCG. There is ample high quality research space. It is anticipated that successful applicants will be eligible for appropriate academic appointments within the Department of Medicine at the MCG. Mixed (VAMC and MCG) appointments are available.

The Department of Medicine at MCG recently was invigorated by a new chair, Dr. John Hardin, who was recruited from Yale. Twenty new faculty are being recruited. A major recommitment to outpatient teaching (new $\$ 40$ million ambulatory care center); research (\$20 million building beginning in 1993); and general internal medicine (Robert Wood Johnson Foundation grant) attest to an important institutional renewal.

Both the VAMC, Augusta and the MCG are equal opportunity employers and solicit letters of interest with references. Additional information is available from Dr. J. Peter Rissing, Chief, Infectious Disease Section. Letters of interest should be sent to Dr. Rissing at Veterans Administration Medical Center, 1 Freedom Way (11lG), Augusta, GA 309046285.

\title{
Fellowship in Hospital Epidemiology
}

Applications are being accepted for a Fellowship in Hospital Epidemiology at the College of Medicine, University of Tennessee, Memphis, for July 1, 1993. The program includes training in biostatistics, hospital epidemiology, infection control, outbreak investigation, use of computers in hospital epidemiology, and hospital epidemiology research. Fellows will conduct one or two prospective epidemiologic studies during the Fellowship. Funds are provided for books, journals, and travel to scientific meetings. Candidates should hold an MD degree and have at least three years of postgraduate training in a medical specialty. For more information about the Fellowship, write to C. Glen Mayhall, MD; Division of Infectious Diseases; University of Tennessee, Memphis; 956 Court Avenue, Room H308; Memphis, TN 38163; or call (901) 5285730.

Brief items of interest for the SHEA News or Newsletter may be sent to C. Glen Mayhall, MD, SHEA, Newsletter Editor, Division of Infectious Diseases, Department of M edicine, University of Tennessee, M emphis, 956 Court A ve., M emphis, TN 38163; FAX (901) 528-5854. Copy should be typed, double-spaced, and should not exceed five pages. 


\title{
펴픅ㄱ
}

\author{
The Third Annual Meeting of \\ The Society for Hospital Epidemiology of America \\ April 18-20, 1993 - Chicago, Illinois
}

\section{CALL FOR ABSTRACTS}

The Society for Hospital Epidemiology of America invites you' to attend the 1993 annual meeting of the Society, April 18-20 in Chicago, Illinois. The two and one-half day program will be devoted to broad epidemiological issues relating to adverse clinical outcomes, nosocomial infections, occupational risks of health-care workers, and quality assessment in adult, pediatric, and long-term care settings. The conference will feature symposia with invited speakers, oral and poster presentations, and round table discussions with audience participation. The meeting is of immediate importance to physicians and infection control practitioners, quality assurance professionals, and administrators in all health-care settings.

\section{CALL FOR ABSTRACTS}

To be considered, abstracts must be submitted on the official abstract form (see below) before January 8 , 1993. A limited number of "Late Breaker" abstracts on recent investigations (e.g. outbreaks) or studies of national importance will be considered if submitted before March 5, 1993.

\section{THE SUBJECT CATEGORIES}
A. Outbreaks
E. Product evaluation
I. Quality Assessment
M. Pediatric
B. Surveillance
F. Disinfection and sterilization
C. Employee Health
G. Prevention and control
D. Device-related infection
H. Antimicrobials-prophylaxis of nosocomial infection
J. Adverse drug event
N. Long-term care
K.Non-infectious adverse outcomes
0. LATE BREAKER
L.HIV/AIDS/Hepatitis
P. Other

\section{ABSTRACT FORMS}

To obtain an official abstract form, mail or fax the coupon below to SHEA headquarters or telephone (609) 845-1720, fax (609) 853-0411

Please mail Official Abstract Forms for the Third Annual Meeting of SHEA, to:

Name:

Address:

Telephone No.: 